\title{
Percursos escolares exitosos entre alunos de camadas populares: socialização familiar e trajetórias sociais
}

\author{
Successful school paths among students from lower class: \\ family socialization and social trajectories
}

\section{Recorridos escolares exitosos entre estudiantes de estratos populares: socialización familiar y trayectorias sociales}

Vanessa Gomes de Castro*
Fernando Tavares Júnior

\section{Resumo}

\begin{abstract}
Investigam-se processos de socialização primária e secundária associados a percursos escolares exitosos entre alunos provenientes de camadas populares. Analisam-se casos bem-sucedidos entre a geração escolar que ingressou no primeiro ano do ensino fundamental em 2006, em uma escola municipal no interior de Minas Gerais, sendo a primeira coorte submetida às leis de ampliação da duração do ensino fundamental para nove anos, com ingresso aos 6 anos de idade. Para aprofundar a análise, foram pesquisadas as histórias de vida de três alunos aprovados continuamente até a conclusão do ensino médio em 2017, representando exceções em meio a uma geração majoritariamente afetada por reprovações e evasões ao longo de seus percursos. Observou-se que processos de socialização primária (familiar) e secundária (extrafamiliar) podem se apresentar como elementos favoráveis, que se mostram associados a percursos escolares exitosos, corroborando a relevância de atitudes específicas dos adultos sobre as trajetórias sociais das gerações mais novas.
\end{abstract}

Palavras-chave: educação; socialização; percursos escolares; trajetórias sociais; sucesso escolar.

\section{Abstract}

This paper investigates primary and secondary socialization processes associated with successful school paths among students from lower classes. Successful cases are analyzed among the generation that entered the first year of basic school in 2006 in a municipal school in Minas Gerais, the first group submitted to the laws that extended basic school from 8 to 9 years, entering at the age of 6 . To deepen the analysis, the life stories of three students continuously approved until the graduation from high school in 2017 was researched, representing exceptions in the middle of a generation mostly affected by reprobation and evasion throughout their path. It was noted that the processes of primary (family) and secondary socialization (school and "neighborhood") may

Recebido em: 22/07/2020 - Aprovado em: 15/04/2021

http://dx.doi.org/10.5335/rep.v28i1.11366

Doutora e mestra em Ciências Sociais pelo Programa de Pós-Graduação em Ciências Sociais da Universidade Federal de Juiz de Fora (PPGCSO/UFJF). Orcid: http://orcid.org/0000-0002-8281-4491. E-mail: vadecastro@hotmail.com

** Professor Associado do Departamento e do Programa de Pós-Graduação em Ciências Sociais da Universidade Federal de Juiz de Fora (UFJF). Bolsista de Produtividade CNPq. Orcid: http://orcid.org/0000-0001-7892-4017. E-mail: ftavares@ caed.uff.br 
be favorable elements associated with successful school paths, stressing the relevance of adults' specific actions over the trajectories of younger generations.

Keywords: education; socialization; school trajectories; school success.

\section{Resumen}

Son investigados procesos de socialización primaria y secundária asociados a trayectorias escolar exitosas entre estudiantes provenientes de estratos populares. Son analisados casos exitosos entre la generación que entró al primer año de la educación basica em 2006, em una escuela del interior de Minas Gerais, el primer grupo sujeto a las leyes de extensión de la educación basica para nueve años, com ingreso a los 6 . Para profundizar el análisis, fueron investigados las historias de vida de tres estudiantes continuamente aprobados hasta la conclusión de sus estudios en 2017, representando excepciones a uns generación mayoritariamente marcada por evasión y reprobación al largo de sus trayectorias. Se observó que los procesos de socialización primaria (família) y secundaria (escuela y "barrio") pueden presentarse como elementos favorables, que se mustran asociados a trayectorias escolares exitosas, corroborando la relevancia de actitudes especificas de los adultos sobre las trayectorias sociales de generaciones más nuevas.

Palabras-Ilave: educación; socialización; recorridos escolares; trayectorias sociales; éxito escolar.

\section{Introdução}

O debate relativo à equalização de oportunidades educacionais tem recebido atenção de pesquisas inspiradas na Teoria do Capital Humano e em diversas abordagens da Sociologia da Educação desde a década de 1960, fomentando amplo debate em torno dos efeitos potenciais da expansão educacional. Nesse sentido, a Sociologia da Educação tem evidenciado que as oportunidades educacionais são bens sociais escassos, distribuídos desigualmente na sociedade, entre as classes sociais, os grupos e os indivíduos, conforme apontado por Bourdieu e Passeron (1970), Jencks et al. (1972), Boudon (1973, 1977), Hirsch (1976), Bourdieu (1979) e outros.

No Brasil, uma sociedade com passado colonial e escravocrata, os processos de "modernização" se iniciaram de fato apenas nos anos 1930, momento em que a educação gratuita, obrigatória e laica entrou na agenda de políticas públicas nacionais, vindo a se efetivar como um direito social somente na segunda metade do século $\mathrm{XX}$, quase um século depois de vários países industrializados. Na Constituição Federal de 1988 e na Lei de Diretrizes e Bases da Educação Nacional de 1996, o direito à educação gratuita e de qualidade foi ratificado, sinalizando o processo de democratização das oportunidades educacionais e redesenhando a estrutura e funcionamento dos sistemas de ensino. Não obstante, o processo de Reforma Educacional continuou em marcha, com a aprovação de uma série de mudanças nos 
anos seguintes. Diversas políticas públicas e legislações educacionais, sobretudo nos últimos anos do século XX e início do século XXI, aprofundaram as tendências de reforma educacional, no sentido de democratizar ainda mais o acesso, ampliar a permanência e retomar os esforços para elevar a qualidade do ensino como expressões do direito à educação e equalização das oportunidades educacionais e sociais. No entanto, apesar das medidas oficiais, constata-se que muito ainda precisa ser feito em termos de qualidade e equidade, tendo em vista, principalmente, os grupos em contexto social e econômico desfavorecido.

Nesse sentido, as principais iniciativas voltam-se para a promoção da aprendizagem e a elevação da aprovação. Com a democratização do acesso, tanto os indicadores de proficiência (desempenho), quanto os relativos à aprovação (rendimento), passaram a ser evidenciados e questionados. Desde o final dos anos 1980, diversas pesquisas, como aquelas desenvolvidas por Fletcher e Ribeiro (1987), Ribeiro (1991), Klein e Ribeiro (1995), apontam o grave problema da repetência massiva ao longo da educação básica, enquanto mecanismo que reforça a distribuição desigual da educação na sociedade, sendo um dos principais problemas do sistema de ensino do país.

Diante disso, o presente trabalho tem como objetivo investigar trajetórias educacionais e processos de socialização adjacentes entre alunos provenientes das camadas populares, os quais participaram da primeira coorte de estudantes submetida às leis que anteciparam a idade de ingresso no ensino fundamental para 6 anos de idade e ampliaram essa etapa da educação básica de 8 para 9 anos, respectivamente Leis no ${ }^{\circ} 11.114 / 2005$ e nํ1․ 11.274/2006, no escopo das Reformas Educacionais supracitadas. Esses alunos ingressaram no $1^{\circ}$ ano do ensino fundamental em 2006 e deveriam concluir o $3^{\circ}$ ano do ensino médio em 2017. Realizaram-se assim, três estudos de caso com alunos que foram aprovados em todas as etapas, concluindo a escolarização básica na idade adequada, constando como exceções à sua coorte, cuja maioria sofreu retenções, interrupções, evasões e reprovações ao longo de suas trajetórias educacionais.

É importante frisar que um dos focos principais das Leis no 11.114/2005 e $\mathrm{n}^{\mathrm{o}}$ 11.274/2006 é a inclusão social, cujos maiores beneficiados são as crianças oriundas das classes populares, ou seja, aquelas que se encontram em contexto social e econômico desfavorável. De modo geral, essas legislações educacionais implantadas no Brasil a partir de 2006 constituem um esforço legítimo para ampliar as oportunidades a mais crianças, a partir do direito de frequentar mais cedo uma escola pública, gratuita e de qualidade (BRASIL, 2005; BRASIL, 2006; SAVELI, 2008). 
De outro lado, é conhecido que os problemas do ensino fundamental se refletem no ensino médio. Nesse sentido, o ensino médio já passou por sucessivas reformas, muitas das quais não lograram tanto êxito, em grande parte em função dos desafios herdados dos níveis anteriores. Para alunos oriundos de segmentos sociais médios e altos, cursar o ensino médio com caráter propedêutico tornou-se natural, visto que o diploma superior faz parte de sua estrutura de capitais culturais e simbólicos, tanto em função do caráter reprodutivo (BOURDIEU, 1979), quanto do consumo defensivo (HIRSCH, 1976). Para esses jovens, há uma motivação intrínseca às recompensas e à própria trajetória de seu grupo social de referência, bem como um amplo aparato de apoio (familiar, escolar, etc.) à sua trajetória educacional (CASTRO; TAVARES JR., 2016).

A questão central recai, portanto, sobre os jovens oriundos de camadas sociais mais pobres, para os quais o ensino médio não faz parte de seu capital cultural e sua experiência familiar. Não há grandes expectativas nem investimentos específicos relativos à continuidade aos estudos. Para esses jovens, a realização dos objetivos modernos e democráticos da educação é limitada pelos empecilhos impostos por suas origens sociais, aliados às desigualdades de oportunidades. Isso se reflete no rendimento nesta etapa. Embora o número de alunos matriculados no ensino médio tenha aumentado significativamente nos últimos anos, menos de $60 \%$ dos jovens conseguem terminar essa etapa, sobretudo no tempo e idade adequados, sem reprovação ou evasão (CASTRO; TAVARES JR., 2016).

Frente a esse quadro, torna-se importante compreender os sentidos que os jovens das camadas populares atribuem à sua escolarização, considerando tanto a classe social e o background familiar, quanto as experiências, singularidades, temporalidades e biografias, no contexto da socialização familiar e interação social. Dayrell e Jesus (2016), ao investigarem processos de exclusão escolar entre jovens adolescentes de 15 a 17 anos, cursando o ensino médio no Brasil, através de grupos focais e entrevistas, defendem que, para compreender as trajetórias escolares e os múltiplos fatores que vêm gerando a exclusão dos jovens é fundamental situá-los como sujeitos socioculturais. Isso implica compreendê-los enquanto indivíduos que possuem uma historicidade, visões de mundo, escalas de valores, sentimentos, emoções, desejos, projetos, lógicas de comportamentos e hábitos que lhes são próprios, apesar da macroestrutura apontar, a princípio, um leque mais ou menos definido de opções em relação a um destino social, bem como as experiências que cada um dos jovens adolescentes terá acesso (DAYRELL; JESUS, 2016). 
Diante dos múltiplos fatores que incidem sobre a produção social de trajetórias escolares, as pesquisas em Sociologia da Educação, desde os anos 1960, têm apontado as correlações entre origem social e a realização educacional. Dentre alguns estudos que alcançaram maior notoriedade internacional está a Reprodução, de Bourdieu e Passeron (1970) e a Distinção, de Bourdieu (1979), que apontam as diferenças culturais como decisivas para reprodução das estruturas de capitais - incluindo escolares. Além das análises baseadas na escolha racional, que relacionam as desigualdades educacionais à posição social e aos campos decisórios, inspiradas nos trabalhos de Boudon (1973, 1977). Contemporaneamente, acrescentam-se os trabalhos dedicados às diferenças na socialização e interação familiar, bem como as pesquisas de Lahire (1997) e Lareau (2007). Evidenciando-se, também, as pesquisas sobre as representações e atitudes de professores, gestores escolares e famílias acerca das probabilidades de sucesso ou fracasso escolar dos indivíduos, sistematizadas por meta-análises como as de Hattie (2009, 2012), entre outras.

Visando contribuir com os conhecimentos científicos sobre a produção social da educação e suas desigualdades, esse trabalho investiga processos de socialização adjacentes a trajetórias escolares exitosas, isto é, cujos sujeitos concluíram a educação básica sem defasagem, apesar dos contextos sociais desfavoráveis. Posto isso, importa destacar que o objetivo do presente trabalho é tomar os conceitos de socialização e interação social para compreender processos associados às trajetórias escolares bem-sucedidas entre indivíduos das camadas populares. Todavia, os processos de socialização e interação social vão muito além das práticas evidenciadas por essa pesquisa.

\section{Processos de socialização e trajetórias escolares}

Os processos de socialização e interação social têm sido amplamente evidenciados pela Sociologia, desde o seu surgimento ao final do século XIX até os dias de hoje. Durkheim (1987), considerado um dos fundadores desta ciência moderna, se preocupou, dentre outras questões, com os processos de socialização primária e secundária das novas gerações. Nesse sentido, a educação escolar, no âmbito da socialização secundária ou extrafamiliar, teria como função o preparo sistemático das crianças e dos jovens, visando a sua integração ao grupo, a coesão social, a divisão do trabalho, a solidariedade e o bom funcionamento da sociedade. Weber (1992), por sua vez, voltou-se ao estudo da ação social, representada pela interação recíproca entre duas ou mais pessoas, em que o sentido está relacionado ao com- 
portamento do outro, tendo como base os significados socialmente compartilhados (racionalidades, valores, emoções e tradições). Na ação social, a educação é um instrumento de poder, estando relacionada à classe social e ao status.

Simmel (2006), outro importante autor da Sociologia, percebe a sociedade como resultante das múltiplas formas de interação, orientadas por padrões culturais e valores sociais dominantes. A interação entre sujeitos é considerada uma forma de sociação, constituída pelas motivações, interesses e objetivos dos indivíduos. Para Elias (1994), a sociedade está baseada em redes de interdependência entre os indivíduos, com complexas configurações. Desde a mais tenra idade, os indivíduos são socializados nessas redes, por exemplo, através das formas de educação. Goffman (2011) também contribuiu com a compreensão da interação social, em que os atores, situados no tempo e espaço, se encontram face a face em situações sociais, se relacionando, se comunicando, agindo conforme as regras apreendidas através dos processos de socialização. Na Psicologia Social, Mead (1972) evidenciou a relação entre o indivíduo e a sociedade, a interação social e a constituição do self, através de processos comunicativos embasados em identidades, aprendizagens familiares, religiosas, educacionais e outros processos de socialização.

$\mathrm{Na}$ Sociologia da Educação, as investigações sobre os processos de socialização e interação social, principalmente relacionados às práticas e às estratégias familiares por trás das trajetórias escolares dos indivíduos, recebem histórica atenção. As investigações sobre as desigualdades perante o ensino deixaram de se caracterizar, exclusivamente, por abordagens macrossociológicas, e passaram a aprofundar processos microssociológicos inerentes à família e à vida escolar. São pesquisadas desde as estratégias educacionais das famílias e dos indivíduos para alcançar o sucesso escolar da prole, até a fenomenologia e a etnometodologia envolvendo o cotidiano da família, da escola e da sala de aula (FORQUIN, 1995; NOGUEIRA; FORTES, 2004).

Nessa direção, Lareau (2007) investigou nos Estados Unidos, nos anos 1990, através de etnografia, como a interação familiar poderia oferecer aos membros do grupo recursos materiais e simbólicos voltados à sua formação escolar. Observou um grupo de famílias de classe média, negras e brancas, identificando, entre essas, estratégias mais visíveis de racionalização da formação escolar dos filhos, por exemplo, através de atividades extraescolares, o uso adequado da linguagem, pouco envolvimento com a família estendida. Já entre as famílias da classe trabalhadora, negras e brancas, no que tange a interação com os filhos e sua formação escolar, a autora identificou a seguinte estratégia: com amor, comida, apoio, segurança os 
filhos terão trajetórias escolares e sociais bem-sucedidas. Nesses casos, existiam poucas atividades organizadas, bastante ênfase nos talentos especiais dos filhos e ligações mais ricas e profundas com suas famílias estendidas. Lareau (2007) conclui que os pais que compartilham a mesma classe social, também compartilham maneiras semelhantes de lidar com a trajetória escolar dos filhos, independe da cor, observando, assim, semelhanças nos processos de socialização.

Lahire (1997) investigou na França, nos anos 1990, através de estudos de caso, o sucesso escolar "improvável” nos meios populares, buscando analisar processos de socialização familiar por trás dos jovens que tiveram o percurso escolar longínquo, rumo a cursos universitários prestigiados, indo além do esperado, dado seu baixo background familiar e social. Lahire (1997) identificou e descreveu as configurações familiares, a cultura da escrita, as condições econômicas, as formas de autoridade familiar e de investimento pedagógico. Concluiu que somente a existência objetiva de capital cultural no seio de uma família não diz nada sobre as relações sociais, a frequência das relações sociais e as maneiras através das quais se transmite (ou não) o capital cultural. A experiência de vida dos indivíduos não poderia ser deduzida do seu pertencimento a uma única coletividade ou classe social, tornando-se necessário considerar os processos de socialização e interação social.

No Brasil, Nogueira $(1998,2005,2006,2010)$ tem investigado a lógica que regula as estratégias das famílias no que tange à escolarização dos filhos, sejam as famílias das camadas populares ou mesmo as estratégias das elites. Segundo Nogueira (2005), as estratégias das famílias buscam manter ou melhorar a posição social do grupo familiar. Estariam relacionadas ao senso prático, sendo as prováveis respostas dadas pelos indivíduos e grupos segundo as suas disposições e predisposições adquiridas em seu meio social de origem. Portanto, relaciona-se ao habitus de classe, à posse de capitais materiais e simbólicos, sob a égide do clássico argumento bourdiesiano.

Nesse sentido, Viana (1998) analisou ao longo dos anos 1990 o sucesso escolar “inesperado" ou "estatisticamente improvável" nas camadas populares. O principal indicador de sucesso utilizado foi o acesso ao curso superior. Buscou compreender o que tornou possível uma escolarização prolongada de indivíduos cuja probabilidade de chegar à universidade é estatisticamente reduzida. Investigou universitários oriundos de famílias com dificuldades econômicas e baixo nível de escolaridade. Concluiu que famílias populares participam da construção do sucesso escolar dos filhos, de modo diferenciado, ainda que nem sempre voltado explícita e objetivamente para tal fim, ressaltando as diferenciações nos processos de socialização. 
Zago (2000) também examinou aspectos da socialização familiar, sobretudo o envolvimento dos pais, especialmente das mães, nas trajetórias escolares dos filhos, nos meios populares. Sua pesquisa foi realizada entre os anos de 1991 e 1993. Em suas conclusões, aponta que a mobilização das famílias para que os filhos tenham uma trajetória escolar bem-sucedida não é o único determinante dos seus destinos escolares, embora possa desempenhar um papel importante e mesmo fundamental na carreira escolar do filho. A mobilização das famílias não é condição suficiente para garantir sua permanência na escola e reduzir as desigualdades escolares.

Outros autores, como Portes (2001), Piotto (2008) e Lacerda (2014), também investigaram processos de socialização e mobilização familiar nos meios populares, em direção à trajetória educacional dos filhos, chegando a resultados congruentes. Além desses, destacam-se trabalhos recentes, como aqueles que constam nos livros organizados por Romanelli, Nogueira e Zago (2013) e Piotto (2014), que demonstram as variações dos padrões atitudinais de pais e filhos conforme a classe social, o nível de instrução, o tipo de família, a divisão de papéis educativos entre pai e mãe, as relações sociais e afetivas no cotidiano da família, dentre outros aspectos em direção à realização escolar.

No presente trabalho, os processos de "socialização" representam as relações construídas face a face no contexto doméstico e extradoméstico. "Trajetórias escolares" se referem aos percursos dos indivíduos através do sistema de ensino, tanto durante o interstício de escolaridade compulsória, isto é, entre o $1^{\circ}$ e o $9^{\circ}$ ano do ensino fundamental, bem como o $1^{\circ}$ ao $3^{\circ}$ ano do ensino médio. Considera-se bem-sucedida a trajetória ininterrupta, sem reprovação ou evasão escolar, que não gera defasagem idade-série e eleva as probabilidades de continuidade dos estudos. O perfil investigado volta-se para alunos que percorreram a educação básica em escolas públicas de redes municipais e estaduais. As "camadas populares" são representadas por grupos sociais cujas circunstâncias gerais de inserção social apresentam limites ao acesso a melhores condições de escolarização/socialização, como origem familiar com baixo nível socioeconômico e baixa escolaridade. A literatura sociológica nos ensina que a origem socioeconômica do aluno pode facilitar ou dificultar sua trajetória escolar. Fatores como as características individuais, o background familiar, a socialização, a interação social, a estrutura de oportunidades educacionais e a legislação, interferem nos destinos escolares dos indivíduos e grupos, assim como na produção e reprodução social das desigualdades perante o ensino.

Exposto esse quadro teórico e conceitual, o presente trabalho teve por objetivo investigar os processos de socialização associados a trajetórias escolares de alu- 
nos, oriundos de famílias das camadas populares, que obtiveram sucesso escolar na educação básica. Essas trajetórias participaram da primeira coorte de alunos matriculados em uma determinada escola pública da rede municipal, totalmente submetida às leis que instituíram a matrícula obrigatória no $1^{\circ}$ ano do ensino fundamental aos 06 anos de idade e a ampliação desta etapa para 09 anos. Logo, esses alunos ingressaram no $1^{\circ}$ ano do ensino fundamental em 2006 e deveriam concluir essa etapa em 2014, ingressando no $1^{\circ}$ ano do ensino médio em 2015 , concluindo este nível da educação básica em 2017. Realizaram-se estudos de caso com três alunos que não foram reprovados ou evadidos ao longo do percurso, concluindo a escolarização básica na idade adequada, com sucesso.

\section{0 local e os sujeitos da pesquisa}

O início das trajetórias escolares, isto é, seu ingresso no $1^{\circ}$ ano do ensino fundamental, foi pesquisado em uma escola pública da rede municipal de uma cidade de porte médio no interior de Minas Gerais. Tal escola possui similitudes com boa parte das escolas urbanas das periferias brasileiras. Seu Índice de Desenvolvimento da Educação Básica (Ideb) variou entre 4.4 (menor índice) e 6.0 (maior índice), entre 2005 e 2015, nos anos iniciais do ensino fundamental; e entre 3.3 (menor índice) e 5.2 (maior índice), entre 2005 e 2015, nos anos finais do ensino fundamental. Segundo o Instituto Nacional de Estudos e Pesquisas Educacionais Anísio Teixeira (Inep), em 2015, a escola contava com, aproximadamente, 506 matrículas, 25 turmas, 11 salas de aula, 46 professores, 03 turnos de funcionamento, atuando nas modalidades pré-escola (poucas turmas), anos iniciais e finais do ensino fundamental e educação de jovens e adultos (noturno).

A escolha desta escola se deu por suas características típicas, tendo sido selecionada para integrar a amostra do Projeto "Determinantes do Sucesso Educacional no Brasil", que teve o apoio do Observatório da Educação: parceria entre a Coordenação de Aperfeiçoamento de Pessoal de Nível Superior (Capes), o Instituto Nacional de Estudos e Pesquisas Educacionais Anísio Teixeira (Inep) e a Secretaria de Educação Continuada, Alfabetização, Diversidade e Inclusão (Secadi). Esta escola apresenta potencialidades e desafios similares à boa parte das escolas de ensino fundamental de porte médio no Brasil, situada em um bairro popular, onde é possível observar as trajetórias escolares típicas das camadas populares.

A primeira fase da pesquisa investigou trajetórias escolares de todos os alunos ingressantes no primeiro ano em 2006, submetidos às leis que instituíram a matrí- 
cula obrigatória no $1^{\circ}$ ano do ensino fundamental aos 6 anos de idade e a ampliação desta etapa para 9 anos. Buscou-se examinar se tais mudanças contribuíram com a regularidade da maioria das trajetórias percorridas em uma determinada escola pública, entre 2006 e 2014. Acompanharam-se os alunos através de diários de classe e atas de resultado final, monitorando a cada ano os alunos aprovados, reprovados, evadidos e transferidos, entre o $1^{\circ}$ e o $9^{\circ}$ ano do ensino fundamental.

Assim, a partir dos resultados desse primeiro estudo longitudinal/documental, constatou-se que, no contexto investigado, dos 53 alunos matriculados no $1^{\circ}$ ano do ensino fundamental em 2006, apenas 20 conseguiram concluir o $9^{\circ}$ ano em 2014 com sucesso, ou seja, percorreram esta etapa no tempo e idade adequados, sem reprovação ou evasão. Por outro lado, identificou-se que, em 2014, quando todos os alunos monitorados deveriam concluir o $9^{\circ}$ ano ensino fundamental, a reprovação escolar havia atingindo, pelo menos, 21 trajetórias ao longo desta etapa, sendo o ponto mais nevrálgico dos percursos escolares no contexto observado, impedindo praticamente metade dos alunos de concluir o ensino fundamental no tempo e idade adequados.

Diante dos poucos casos de sucesso, dada a massiva reprovação, bem como os múltiplos fatores que concorrem para a reprodução de desigualdades educacionais, o presente trabalho buscou identificar fatores relacionados à socialização e à interação social por trás de algumas trajetórias escolares relativamente bem-sucedidas. Nesse sentido, uma vez identificados os alunos que foram aprovados em todos os anos do ensino fundamental, do $1^{\circ}$ ao $9^{\circ}$, de 2006 a 2014 , rastrearam-se seus status educacionais em 2017, quando deveriam estar concluindo o $3^{\mathrm{o}}$ ano do ensino médio, realizando-se estudos de caso com alguns desses alunos sobre seus processos de socialização: objeto do presente trabalho.

\section{Metodologia}

Através de estudos de caso e histórias de vida, buscou-se examinar detalhadamente a construção de trajetórias escolares de alunos oriundos das camadas populares, no âmbito dos processos de socialização primária e secundária. Para tanto, realizaram-se entrevistas com os alunos cujas trajetórias foram bem sucedias até o final da educação básica, atentando-se para a manifestação de fatores considerados pela literatura cientifica como determinantes dos destinos escolares, isto é: fatores individuais, como sexo e cor; fatores familiares, os quais remetem à posição social da família e à posse de capital econômico, cultural e social, como a 
escolaridade de avós, pais e irmãos, à ocupação dos avós e dos pais, ao incentivo familiar aos estudos, bem como ao acesso a oportunidades sociais, além de fatores relacionados aos processos de socialização, como a participação em grupos extrafamiliares, o ingresso no mundo do trabalho, etc.

As trajetórias foram investigadas longitudinalmente. Monitoraram-se todos os alunos da coorte selecionada a cada ano, verificando aqueles que foram aprovados, reprovados, evadidos e transferidos, com base em diários de classe e atas de resultado final. Em 2017, rastrearam-se, dentre os alunos que concluíram com sucesso o ensino fundamental em 2014, aqueles que chegaram com êxito ao $3^{\circ}$ ano do ensino médio em 2017. Selecionaram-se 03 casos exemplares que foram entrevistados espontaneamente acerca de suas trajetórias escolares, dos atores e instituições envolvidos, as relações sociais, além de eventos marcantes em suas vidas.

\section{Primeiro caso: Gisele ${ }^{1}$}

Gisele ingressou no $1^{\circ}$ ano do ensino fundamental em 2006, aos 7 anos de idade. Percorreu os nove anos do ensino fundamental sem ser reprovada ou evadir da escola. Gisele é do sexo feminino e se autodeclara negra. Em 2017, cursava o $3^{\circ}$ ano do ensino médio em uma escola pública da rede estadual de ensino e não trabalhava fora de casa. Aos 18 anos, era solteira e sem filhos. Morava com o pai e o irmão caçula.

Nascida em Juiz de Fora, sua família era composta por pai, mãe e cinco irmãos, com idades de 11, 19, 20, 23 e 25 anos. Se autodeclaravam católicos. Todos nasceram em Juiz de Fora. Gisele teve contato somente com os avós paternos, que eram analfabetos - seu avô trabalhava na roça e sua avó era dona de casa. Seu pai estudou até a $4^{\mathrm{a}}$ série do ensino fundamental e trabalhava como autônomo na profissão de pedreiro. Sua mãe também estudou somente até a $4^{a}$ série do ensino fundamental e trabalhava como doméstica, porém estava desempregada. Seu irmão de 11 anos de idade estava cursando o $6^{\circ}$ ano do ensino fundamental em 2017. Sua irmã de 19 anos parou de estudar no $1^{\circ}$ ano do ensino médio. Sua irmã de 20 anos parou de estudar na antiga $6^{\mathbf{a}}$ série do ensino fundamental. Sua irmã de 23 anos parou de estudar no $1^{\circ}$ ano do ensino médio. Seu irmão de 25 anos também parou de estudar na antiga $6^{\mathrm{a}}$ série do ensino fundamental.

Gisele ingressou no primeiro período da educação infantil aos 4 anos de idade, na escola pública municipal próxima de sua residência. Aos 5 anos seguiu para o segundo período da educação infantil e aos 6 anos concluiu o terceiro período. Aos 
7 anos de idade, ingressou no $1^{\circ}$ ano do ensino fundamental nessa mesma escola, em que permaneceu estudando até o $9^{\circ}$ ano do ensino fundamental, concluído aos 15 anos de idade (um ano a mais em relação à idade ideal - 14 anos -, visto que ela ingressou no ensino fundamental de 9 anos aos 7 anos de idade, isto é, acima da idade ideal recomendada pelas reformas educacionais -6 anos). Gisele nunca foi reprovada ou evadiu da escola ao longo dessa etapa, cursando o ensino regular diurno. Ao longo de sua escolarização, sua família chegou a receber Bolsa Família por um determinado tempo.

Ao concluir o ensino fundamental, Gisele ingressou no ensino médio em uma escola pública da rede estadual, situada em um bairro um pouco mais distante de sua residência. Ela e sua família consideravam essa escola de maior qualidade em relação à escola localizada no bairro em que moravam. Acreditavam que essa escola mais prestigiada aumentaria as chances de aprovação em processos seletivos para a universidade. Além disso, os amigos de seus pais também enviariam os filhos para essa escola pública considerada melhor. Assim, Gisele cursou o ensino médio pela manhã, no ensino regular. Estava matriculada no $3^{\circ}$ ano do ensino médio em 2017, aos 18 anos de idade recém-completos.

Ao longo do ensino médio Gisele prestou o Programa de Ingresso Seletivo Misto (PISM) da Universidade Federal, módulo I e II. Ao final do ano de 2017 pretendia realizar o módulo III. Acreditava que teria nota suficiente para ingressar no curso de Pedagogia na Universidade Federal. Também pretendia tentar o Exame Nacional do Ensino Médio (Enem), caso não conseguisse obter nota pelo PISM para os cursos de Pedagogia ou Psicologia. Ela é inscrita no grupo de cotas raciais e para estudantes de escolas públicas. Estuda em casa, por conta própria, de acordo com as tarefas diárias. Mora com o pai e o irmão mais novo, pois seus pais se divorciaram e os irmãos mais velhos são casados residindo em outros lugares. Assim, ela é encarregada das tarefas domésticas de sua casa.

A primeira atividade remunerada de Gisele foi como babá. Começou a exercer essa atividade aos 14 anos de idade, quando ainda estava terminando o ensino fundamental. Ela conta que, na época, uma amiga de sua mãe pediu para ela cuidar de seus filhos de modo remunerado. Ela aceitou, permanecendo nessa atividade até os 17 anos de idade, quando estava no final do $2^{\circ}$ ano do ensino médio. Aos 18 anos, no $3^{\circ}$ ano do ensino médio, dedicava-se principalmente aos estudos.

Em relação a cursos profissionalizantes, Gisele disse que chegou a ingressar em um curso de informática, porém não concluiu, pois a família não teve condições de arcar com o curso até o final. Ela também chegou a fazer cursinho em uma ins- 
tituição privada, para prestar processos seletivos militares, no entanto, não chegou a realizar as provas. Segundo Gisele, inicialmente o pai arcava com o cursinho e, posteriormente, ela arrumou uma atividade remunerada para ajudar a arcar. Contudo, havia muitas taxas (como inscrições e etc.) não previstas no orçamento e, por isso, ela não realizou os exames.

Para Gisele, o maior incentivador de sua trajetória escolar era o seu pai. Caso não passasse nos processos seletivos para a universidade pública ao final de 2017, o pai tinha se oferecido para arcar com uma faculdade particular para ela não ficar um ano sem estudar. O pai não queria que a filha "perdesse um ano tentando novamente". Segundo Gisele, a mãe sempre participou de sua vida escolar, era quem ia às reuniões da escola, porém, o pai era quem ajudava com os deveres de casa. De acordo com ela, "meu pai diz que a gente tem que estudar para ser alguém na vida". Conta que o pai mantém o pulso firme com ela e o irmão mais novo, porque os outros irmãos já se afastaram da escola. Seu pai diz que: "não conseguiu estudar, mas quer que os filhos consigam". Ela diz que o pai sempre arcou com tudo dentro de suas possibilidades, como o transporte para a escola, eventos extraescolares etc.

Além do pai, Gisele contou que a mãe de seu namorado também incentivava muito seus estudos, dizendo que: "ela tinha que ser uma mulher independente". Segundo Gisele, a escola era uma de suas principais fontes de informação sobre as possibilidades de continuar os estudos. Ressaltou que os diretores e coordenadores conversavam com os alunos, indicavam processos seletivos, explicavam como conseguir isenção para a inscrição etc. Em relação aos planos para o futuro, disse que pretende concluir uma faculdade, conseguir um bom emprego, estabilizar-se e depois construir uma família.

\section{Segundo caso: Marina}

Marina, o segundo caso, ingressou no $1^{\circ}$ ano do ensino fundamental em 2006, aos 7 anos de idade. Percorreu o ensino fundamental sem ser reprovada ou evadir da escola. Marina é do sexo feminino e se autodeclara parda. Em 2017 estava cursando o $3^{\circ}$ ano do ensino médio e dedicava-se somente aos estudos. Aos 18 anos, era solteira e sem filhos. Morava com os pais.

Nascida na cidade de Juiz de Fora/MG, sua família nuclear era composta por pai, mãe e a filha única. Se autodeclaravam evangélicos. Seus avós maternos e paternos nasceram em outra cidade do estado de Minas Gerais. Seus avós maternos eram analfabetos - sua avó materna era lavadeira e seu avô materno carpinteiro e 
pedreiro. Seus avós paternos estudaram até a $2^{\mathrm{a}}$ série do ensino fundamental - sua avó paterna era dona de casa e seu avô trabalhava com gado. Sua mãe estudou até a $8^{\mathrm{a}}$ série do ensino fundamental e trabalhava como costureira autônoma. Seu pai estudou até a $4^{\mathrm{a}}$ série do ensino fundamental e trabalhava como frentista e vigia noturno.

Marina ingressou no primeiro período da educação infantil aos 3 anos de idade, em uma escola particular de tempo integral, situada no bairro vizinho ao que morava. Aos 4 anos seguiu para o segundo período e aos 5 anos de idade concluiu a educação infantil. No entanto, quando os pais de Marina foram matricular a filha no $1^{-}$ano do ensino fundamental, na escola pública municipal do bairro, uma vez que ela havia ingressado na educação infantil abaixo da idade recomendada, ela teve a sua matrícula indeferida, devido à coorte etária (idade mínima de 6 anos completos). Diante disso, a escola propôs que ela cursasse novamente o segundo período da educação infantil, até chegar à idade "adequada", e assim ela o fez.

Aos 7 anos de idade, Marina ingressou no $1^{\circ}$ ano do ensino fundamental. Nesse momento, ela já havia cursado o segundo período da educação infantil por duas vezes e já tinha aprendido a ler e a escrever, e, até mesmo, esboçar letra cursiva, destacando-se dos colegas de turma. Segundo ela, seus pais foram chamados à escola diversas vezes, devido à filha ser adiantada em relação à turma. Marina cursou o ensino fundamental diurno e regular, sem ser reprovada ou evadir da escola, concluindo essa etapa em 2014.

Ao concluir o ensino fundamental, ela e sua família optaram por uma escola pública estadual, em suas palavras, "de maior qualidade", para cursar o ensino médio, uma vez que consideravam a escola pública estadual do bairro ruim. Contou que ela e os pais pesquisaram várias escolas, até mesmo particulares. Todavia, sua família descartou a escola particular, principalmente devido às possibilidades proporcionadas pelas políticas de cotas no ensino superior para estudantes de escolas públicas. Segundo ela, sua mãe sempre acreditou nos "nossos direitos". "A educação pública é um direito, temos que lutar".

Assim, ela foi matriculada no ensino médio na escola pública estadual considerada de maior prestígio. Ao ingressar no $1^{\circ}$ ano do ensino médio, aos 15 anos de idade, inicialmente, Marina teve problemas de adaptação à nova escola. Disse que tinha medo, era tímida e demorou a se integrar à turma e fazer novas amizades. Posteriormente, adaptou-se. Aos 18 anos de idade, cursava o $3^{\circ}$ ano do ensino médio, nunca foi reprovada ou evadiu da escola, cursando o ensino regular diurno. Seus pais arcavam com o transporte, visto que a escola não era tão próxima de sua residência. 
Ao longo do ensino médio, Marina prestou o Programa de Ingresso Seletivo Misto (PISM) da Universidade Federal. Já prestou o módulo I e II, e, em 2017, prestaria o módulo III. Ela se inscreveu no grupo de cotas raciais e para estudantes de escolas públicas. No $2^{\circ}$ ano do ensino médio ingressou em um cursinho preparatório para o PISM, o qual frequentava duas vezes por semana, em uma instituição particular. Sua mãe era quem arcava com os custos. Marina acreditava que suas notas eram adequadas e que conseguiria ingressar na universidade pública, no curso de Odontologia.

Em relação a cursos diversos, disse que fez informática, quando tinha entre 9 e 10 anos de idade. Também disse que já cursou Inglês, por dois anos, durante o ensino médio - ambos os cursos em instituições privadas, financiados pelos pais. Além desses, Marina fez cursinho para prestar o exame do Instituto Federal de Educação Ciência e Tecnologia do Sudeste, para o curso de Técnico de Metalurgia, porém, alegou que não era bem o que ela queria, pois visava ter tempo para estudar e ingressar na universidade. Assim, ela até obteve nota, mas não quis ingressar no curso técnico, pois, se assim fosse, ela não teria tempo para estudar para o PISM.

Segundo Marina, os pais são os maiores incentivadores de sua trajetória escolar. Além deles, ela diz ter uma amiga um pouco mais velha (que então cursava a faculdade de enfermagem na Universidade Federal), considerada uma das principais pessoas que incentiva e informava sobre as oportunidades, como o PISM e o Enem. Essa amiga é quem falava sobre a importância de fazer uma faculdade. Marina diz que é muito grata a essa amiga e que, se não fosse por ela, talvez nem estivesse na escola. Foi essa amiga quem a levou para conhecer o campus universitário.

Além da família e da amiga, Marina diz que sempre contou com o apoio de alguns professores, principalmente aqueles com quem tinha mais afinidades. Conta que teve graves problemas familiares ao final do ensino fundamental e início do ensino médio, como a depressão da mãe, problemas de saúde e violência na família, e, com isso, alguns professores específicos, dos quais ela se lembra dos respectivos nomes com carinho, foram fundamentais em ajudar a passar por esse momento difícil. Ela conta que também chegou a ter problemas na escola com outros professores, que não sabiam ou entendiam a situação pela qual ela passava.

Marina nunca exerceu atividades remuneradas, exceto algumas vezes em que vendeu pulseiras na escola durante o ensino fundamental, ou, recentemente, quando vendeu cupcake com sua madrinha em uma feira. Segundo ela, os pais nunca a deixaram trabalhar. Ela conta que fez a carteira de trabalho, arrumou emprego, mas os pais embargaram, pedindo para a filha única se dedicar somente aos estu- 
dos. Em relação aos planos para o futuro, diz que pretende concluir a faculdade e montar seu consultório odontológico.

\section{Terceiro caso: Pedro}

O terceiro caso ingressou no $1^{0}$ ano do ensino fundamental em 2006, aos 6 anos de idade, percorrendo o ensino fundamental sem ser reprovado ou evadir da escola. Pedro é do sexo masculino e se autodeclara negro. Em 2017, aos 17 anos de idade, estava cursando o $3^{\circ}$ ano do ensino médio e trabalhava como auxiliar de transporte escolar. Era solteiro e sem filhos. Morava com o pai, a mãe e os irmãos.

Nascido em Juiz de Fora, sua família nuclear era composta por pai, mãe, um irmão de 14 anos e uma irmã de 24 anos de idade. Sua família se autodeclarava católica. Seus avós paternos nasceram em Juiz de Fora. Sua avó paterna estudou até o ensino médio e trabalhou como cozinheira e faxineira. Seu avô paterno era trabalhador rural e Pedro não sabe sua escolaridade. Sua avó materna nasceu no estado da Bahia, era analfabeta e dona de casa. Pedro não teve contato com o seu avô materno. Seu pai nasceu em Juiz de Fora, estudou até o $2^{\circ}$ ano do ensino médio e trabalhava como técnico de purificadores. Sua mãe nasceu no estado da Bahia, estudou até a $7^{\mathrm{a}}$ série do ensino fundamental e trabalhava como copeira, porém estava afastada devido a problemas de saúde. Pedro possui um irmão de 14 anos, que, em 2017, estava cursando o $8^{\circ}$ ano do ensino fundamental, e uma irmã de 24 anos, formada em direito, cursado em uma faculdade particular.

Aos 3 anos de idade, Pedro ingressou em uma creche pública no bairro vizinho. Aos 4 anos de idade, ingressou no primeiro período da educação infantil, na escola pública municipal do bairro. Aos 6 anos de idade, ingressou no $1^{\circ}$ ano do ensino fundamental nessa mesma escola. Cursou essa etapa no ensino regular diurno, sem ser reprovado ou evadir da escola, concluindo em 2014, aos 14 anos de idade. Ao concluir o ensino fundamental na escola pública municipal próxima de sua residência, Pedro e sua família prefiram uma escola pública estadual situada em outro bairro, com o ensino considerado "mais forte", para ele cursar o ensino médio, pois a escola do bairro era considerada muito precária. Contudo, também alegou que sua irmã estudou na escola do bairro e foi para a faculdade. Além disso, diz ter escolhido a "escola melhor", porque seus amigos iriam estudar lá. Durante certo período de sua escolarização, seus pais receberam Bolsa Família.

Aos 15 anos de idade Pedro ingressou no $1^{\circ}$ ano ensino médio e, aos 17 anos, estava cursando o $3^{\mathrm{a}}$ ano. Nunca foi reprovado ou evadiu da escola, estudando no 
ensino regular diurno. Pedro diz que sempre foi um aluno "bagunceiro", que gostava de conversar com os colegas durante as aulas, mas que sempre foi compromissado com a escola e não gostava de tirar notas vermelhas. Segundo ele, "deve ser horrível repetir um ano inteiro". Ao longo do ensino médio, prestou o PISM I e II e, em 2017, prestaria o módulo III. Porém, alega que suas notas não são seriam suficientes para o curso que optou de Engenharia de Produção. Além disso, também pretendia prestar o Exame Nacional do Ensino Médio. Pedro é inscrito no grupo de cotas raciais e para estudantes de escolas públicas. Segundo ele, caso não consiga ingressar pelo PISM, continuará tentando ingressar na universidade pública pelo Enem e, talvez, fará cursinho preparatório.

Pedro começou a exercer atividade remunerada durante o $2^{\circ}$ ano do ensino médio. Alegou que começou a trabalhar não porque precisava ajudar em casa, mas para ter o próprio dinheiro. Seu pai incentivava o trabalho. Sua primeira atividade remunerada, na qual permanecia atuando, era de auxiliar de transporte escolar, exercida em meio turno, depois da escola. Durante o ensino médio, fez um curso profissionalizante de elétrica automotiva, em uma instituição particular. O pai foi quem ofereceu a oportunidade e arcou financeiramente com o curso. Pedro pretendia procurar um emprego na área no próximo ano, quando completasse 18 anos de idade. Em relação a outros cursos, conta que, durante a infância e adolescência, fez escolinha de futebol e aulas de Muay Thai, ambas em instituições privadas. O pai sempre financiou suas atividades.

Segundo Pedro, o pai é o maior incentivador de sua trajetória escolar. Segundo ele, seu pai sempre diz: "se não estudar, vai levar uma coça". A mãe também incentivava a sua trajetória escolar. A mãe era quem ia às reuniões escolares, pois o emprego do pai era menos flexível em termos de horário. Pedro conta que seu pai diz: "você precisa estudar para não ficar igual a mim, trabalhando muito em um trabalho cansativo. Tem que estudar para ter um futuro melhor". Os pais o incentivavam a cursar uma faculdade e buscavam se informar sobre as oportunidades, por exemplo, sobre o PISM e o Enem. De acordo com Pedro, "Deus e a batalha dos pais no dia a dia são seus principais motivadores".

Em 2018, Pedro pretendia se alistar no serviço militar, uma vez que completaria 18 anos. Ele quer servir, pois o seu pai já serviu e diz que: "é bom para aprender a ter mais disciplina”. Pedro também vislumbrava a carreira militar e, ao final de 2017, prestaria o exame da ESA (Escola de Sargentos das Armas). Ele estudava em casa por conta própria, depois do trabalho, porém contou que chegava em casa cansado e queria fazer outras coisas, por exemplo, navegar na internet. Caso não 
passasse, no ano seguinte tentaria novamente. Em suas palavras o plano é "trabalhar, porque não tem outro jeito, e continuar tentando o Enem”.

\section{Discussão sobre os casos e seus processos de socialização e interação social}

Os casos analisados representam trajetórias escolares de jovens nascidos em famílias de camadas populares. No entanto, apesar de semelhanças econômicas, sociais e culturais entre as famílias, essas desenvolvem diferentes maneiras de enfrentar as adversidades sociais relacionadas à origem. Em função de experiências próprias, as famílias desenvolveram estratégias originais de motivar e supervisionar a trajetória escolar dos filhos, guardando traços comuns de um ethos que valoriza a educação, a disciplina e as perspectivas de realização em longo prazo, principalmente quando os filhos se mostram propensos. Em todos os processos de socialização familiar, foi possível perceber indícios de que os pais transmitem, dentro de suas limitações, a importância da educação para o futuro dos filhos para, pelo menos, conseguirem "um bom emprego" e "ser alguém na vida". Todos os casos entrevistados mencionaram a importância que a família atribui à educação, mesmo sem possuir altos níveis de escolaridade.

Diante do reconhecimento da importância da educação, pode-se dizer que as famílias avaliam os benefícios futuros (longo prazo) da educação, buscando investir, dentro de suas possibilidades, também em cursos profissionalizantes, preparatórios para processos seletivos, e atividades de outras naturezas, tais como esportes, almejando melhorar a formação e inserção social dos filhos, somando-se a isso o almejado diploma de nível superior. De um modo ou de outro, os investimentos familiares em cursos profissionalizantes e de outras naturezas proporcionam ambientes diferenciados de socialização, que agregaram valores, motivações, expectativas, hábitos, atitudes e habilidades aos filhos. O núcleo familiar, principalmente os pais, em todos os casos são apontados como os maiores incentivadores e financiadores da trajetória escolar dos sujeitos da pesquisa. Processos de socialização extrafamiliar e a interação social com amigos, vizinhos, namorados e outras pessoas, que incentivam a educação, também ajudaram a direcionar suas trajetórias.

Destaca-se também a forma como é gerido o ingresso no mundo do trabalho. Dentre os três casos examinados, dois já haviam exercido atividade remunerada extrafamiliar, exceto aquele que era filho único, cujos pais não permitiam o trabalho extradoméstico. Os demais começaram a exercer atividades remuneradas fora de casa durante o ensino fundamental e o ensino médio, mas sem que com- 
prometesse nem prejudicasse os estudos. O exercício de atividades remuneradas é justificado pela necessidade de ter o próprio dinheiro, ter um poder de consumo que a família não tem condições de proporcionar, dada a sua situação econômica e social. $\mathrm{O}$ ingresso no mundo do trabalho foi relativamente precoce, mas em tempo parcial e sem comprometer a escola, que continuou sendo prioritária. Aparece como alternativa para preencher o tempo livre, como atividade que agrega disciplina, socialização com pessoas mais maduras e o uso das habilidades e competências aprendidas na escola. "No tipo ideal", nessa idade os jovens deveriam se dedicar somente aos estudos; mas, nesses casos, foi algo complementar e mutuamente reforçado. Nota-se também que aconteceu informalmente, isto é, a atividade é desempenhada junto a um parente ou conhecido, por contrato somente verbal, com baixa remuneração, mas relevante por razões simbólicas.

Quanto à estrutura de oportunidades educacionais e sociais, destaca-se que as políticas públicas de expansão e democratização do ensino superior aparecem em evidência em todos os casos examinados, que usufruíram da ampliação do acesso em função de cotas sociais e raciais. Dentre as políticas sociais, também se destaca a Bolsa Família. Em todos os casos, essas políticas se revelaram importantes para as famílias, para a continuidade educacional e um possível acesso à educação superior. Evidencia-se que jovens das camadas populares têm aspirações educacionais elevadas. Porém, são historicamente escassas as oportunidades. Quando surgem, elas se tornam objeto de intenso desejo e projetos de vida de vários estratos populares.

Dentre as desigualdades que caracterizam a estrutura da sociedade brasileira, quando se inclui o recorte racial, seus contornos se tornam mais severos. Diante disso, no que tange ao acesso à educação superior, os debates públicos sobre as ações afirmativas têm sido polêmicos, gerando extensa produção acadêmica, tanto sobre os princípios das ações afirmativas, como sobre os processos de implantação das políticas de cotas nas instituições de ensino superior e os resultados dessa medida. As cotas nas universidades públicas se justificam a partir da extrema desigualdade racial existente no país, principalmente no que se refere ao acesso ao ensino superior, dadas, dentre outras coisas, a herança escravocrata, a manutenção dos privilégios de classe, o investimento tardio na educação pública, bem como o desigual acesso à estrutura de oportunidades, que caracteriza a sociedade brasileira. Assim, nos últimos anos, tem-se discutido de forma mais efetiva a implantação de políticas sociais que visam a minimizar um quadro considerado inaceitável para um país como o Brasil (LIMA, 2010, 2012). 
Por fim, observou-se que, por trás de trajetórias escolares bem sucedidas entre alunos das camadas populares, além dos processos de socialização e interação familiar mais conhecidos, descritos e analisados, somam-se outros processos sociais (GRANOVETTER, 1983), como oportunidades franqueadas por novas políticas públicas, além das experiências singulares como a forma de inserção no mercado de trabalho, relacionamentos afetivos motivadores e a interação social positiva com parentes, amigos, vizinhos e outros que incentivam a educação. Todos eles participam, de maneiras mais sutis ou mais proeminentes, do processo de construção dessas trajetórias escolares de sucesso.

\section{Considerações finais}

Este trabalho investigou processos de socialização associados a trajetórias escolares de sucesso, entre alunos provenientes das camadas populares. Foi privilegiada a geração escolar 2006, que deveria concluir o $3^{\circ}$ ano do ensino médio em 2017. Realizaram-se estudos de caso com três alunos selecionados desta coorte que foram aprovados continuamente do ensino fundamental ao ensino médio, representando exceções. Observou-se que processos de socialização favoráveis concorreram para o êxito dessas trajetórias. Foi possível identificar que, na socialização primária, apesar da baixa escolaridade e condições socioeconômicas da família, sobressaem-se os incentivos verbais, projeções de expectativas e diálogos relacionados à educação dos filhos, bem como a explícita crença na importância da escola para o futuro dos mesmos. A memorização/interiorização desses valores fica evidente nas falas dos entrevistados. Nesse sentido, a interação familiar através do acompanhamento da vida escolar dos filhos se mostra crucial. Acrescentam-se os financiamentos de atividades educacionais extras, dentro das possibilidades de cada família, através de cursos diversos, contribuindo com o desenvolvimento de habilidades técnicas e pessoais, colaborando para uma inserção social mais promissora.

Nota-se também que, nos processos de socialização, as famílias e os indivíduos cultivam semelhanças e singularidades em suas maneiras de conduzir os processos educativos, com aspirações próprias e motivações ímpares. Destaca-se que as oportunidades proporcionadas pelo núcleo familiar (materiais e simbólicas) são extremamente importantes e grandes diferenciais nas trajetórias. Somam-se a elas as oportunidades educacionais viabilizadas por meio de políticas públicas, fundamentais para garantir o acesso educacional para aqueles que estão em condições desvantajosas. Assim, conclui-se que, apesar do background social dizer muito sobre 
os processos de construção de trajetórias escolares, também se tornou necessário considerar os processos de socialização primária e secundária como capazes de reverter ciclos reprodutores negativos e transmitir valores positivos relacionados à educação e aos seus benefícios.

\section{Nota}

1 Todos os nomes são fictícios para preservar a identidade dos entrevistados, o anonimato dos envolvidos, a confidencialidade dos dados privados e o uso estritamente ético e acadêmico das informações.

\section{Referências}

BOUDON, R. L’inégalité des chances: la mobilité sociale dans les sociétés industrielles. Paris: Armand Colin, 1973.

BOUDON, R. Effets pervers et ordre social. Paris: Presses universitaires de France, 1977.

BOURDIEU, P.; PASSERON, J. C. La Reproduction: Éléments d'une théorie du système d'enseignement. Paris: Les Editions de Minuit, 1970.

BOURDIEU, P. La distinction: critique sociale du jugement. Paris: Les Editions de Minuit, 1979.

BRASIL. Lei no 11.114 , de 16 de maio de 2005. Torna obrigatório o início do ensino fundamental aos seis anos de idade. Brasília, DF, 2005. Disponível em: http://www.planalto.gov.br/ccivil_03/_ ato2004-2006/2005/lei/111114.htm Acesso 20/05/2017. Acesso em: 12 mar. 2020.

BRASIL. Lei n⿳ำ 11.274, de 06 de fevereiro de 2006. Estabelece as diretrizes e bases da educação nacional, dispondo sobre a duração de nove anos para o ensino fundamental. Disponível em: http://www.planalto.gov.br/ccivil_03/_ato2004-2006/2006/lei/111274.htm. Acesso em: 12 mar. 2020.

BRASIL. Ministério da Educação. Secretaria de Educação Básica. Departamento de Políticas de Educação Infantil e Ensino Fundamental. Coordenação Geral do Ensino Fundamental. Ensino Fundamental De Nove Anos - Orientações Gerais. Brasília/2004. Disponível em: http:// portal.mec.gov.br/seb/arquivos/pdf/Ensfund/noveanorienger.pdf. Acesso em: 12 mar. 2020.

CASTRO, V. G.; TAVARES JR., F. Jovens em Contextos Sociais Desfavoráveis e Sucesso Escolar no Ensino Médio. Educação e Realidade, Porto Alegre, v. 41, n. 1, p. 239-258, jan./mar. 2016.

DAYRELL, J. T; JESUS, R. E. Juventude, ensino médio e os processos de exclusão escolar. Educação e Sociedade, Campinas, v. 37, n. 135, p. 407- 423, abr./jun. 2016.

DURKHEIM, E. A Educação Como Processo Socializador: função homogeneizadora e função diferenciadora. In: FORACCHI, M. M.; PEREIRA, L. (org.). Educação e Sociedade: leituras de sociologia da educação. São Paulo: Companhia Editora Nacional, 1987. p. 34-48.

ELIAS, N. A sociedade dos indivíduos. Rio de Janeiro: Jorge Zahar, 1994. 
FLETCHER, P. R.; RIBEIRO, S. C. O ensino de primeiro grau no Brasil de hoje. Em Aberto, Brasília, v. 6, n. 33, p. 1-10, jan./mar. 1987.

FORQUIN, J. C. Sociologia da Educação: 10 anos de pesquisa. Petrópolis: Vozes, 1995.

GOFFMAN, E. Ritual de interação: ensaios sobre o comportamento face a face. Petrópolis, RJ: Vozes, 2011.

GRANOVETTER, Mark. The strength of weak ties: a network theory revisited. Sociological Theory, New Haven, v. 1, p. 201-233, 1983.

HATTIE, J. Visible learning: a synthesis of over 800 meta-analyses relating to achievement. New York: Routledge, 2009.

HATTIE, J. Visible learning for teachers. New York: Routledge, 2012.

HIRSCH, F. Social Limits to Growth. London: Routledge; Kegan Paul, 1976.

JENCKS, C. et al. Inequality: a Reassessment of the Effect of Family and Schooling in America. New York: Basic Books, 1972.

KLEIN, R.; RIBEIRO, S. C. A Pedagogia da Repetência ao Longo das Décadas. Avaliação de Políticas Públicas Educacionais, Rio de Janeiro, v. 3, n. 06, p. 55-62, jan./mar. 1995.

LACERDA, W. M. G. De escolas públicas estaduais ao Instituto Tecnológico de Aeronáutica (ITA). In: PIOTTO, D. C. (org.). Camadas Populares e universidades públicas: trajetórias e experiência escolares. São Carlos: Pedro \& João Editores, 2014. p. 45-88.

LAHIRE, B. Sucesso escolar nos meios populares: as razões do improvável. São Paulo: Ática, 1997.

LAREAU, A. A desigualdade invisível: o papel da classe social na criação dos filhos em Famílias Negras e Brancas. Educação em Revista, Belo Horizonte, n. 46, p. 13-82, dez. 2007.

LIMA, M. Acesso à universidade e mercado de trabalho: o desafio das políticas de inclusão. In: MARTINS, H.; COLLADO, P. (org.). Trabalho e sindicalismo no Brasil e Argentina. São Paulo: Hucitec; Mendonza: Universidad Nacional de Cuyo, 2012. p. 91-111.

LIMA, Márcia. Desigualdades raciais e políticas públicas: ações afirmativas no governo Lula. Novos Estudos CEBRAP, São Paulo, n. 87, p. 77-95, jul. 2010.

MEAD, G. H. Mind, self, and society: from the standpoint of a social behaviorist. Chicago: The University of Chicago Press, 1972.

NOGUEIRA, C. M. M.; FORTES, M. F. A importância dos estudos sobre trajetórias escolares na sociologia da educação contemporânea. Paidéia, Belo Horizonte, v. 3, n. 02, p. 57-74, 2004.

NOGUEIRA, M. A. A escolha do estabelecimento de ensino pelas famílias: a ação discreta da riqueza cultural. Revista Brasileira de Educação, São Paulo, n. 07, p. 42-56, 1998.

NOGUEIRA, M. A. A relação família-escola na contemporaneidade: fenômeno social/interrogações sociológicas. Análise Social, Lisboa, v. 40, n. 176, p. 563-578, 2005.

NOGUEIRA, M. A. Família e escola na contemporaneidade: os meandros de uma relação. Educação e Realidade, v. 31, p. 155-169, 2006. 
NOGUEIRA, M. A. Classes médias e escola: novas perspectivas de análise. Currículo sem Fronteiras, v. 10, n. 01, p. 213-231, jan./jun. 2010.

PIOTTO, D. C. Camadas populares e universidades públicas: trajetórias e experiências escolares. São Carlos: Pedro e João Editores, 2014.

PIOTTO, D. C. Trajetórias escolares prolongadas nas camadas populares. Cadernos de Pesquisa, São Paulo, v. 38, n. 135, p. 701-727, set./dez. 2008.

PORTES, E. A. Trajetórias escolares e vida acadêmica do estudante pobre da UFMG: um estudo a partir de cinco casos. 2001. 259 f. Tese (Doutorado em Educação) - Programa de Pós-Graduação em Educação, Universidade Federal de Minas Gerais, Belo Horizonte, 2001.

RIBEIRO, S. C. A pedagogia da repetência. Estudos Avançados, São Paulo, v. 5, n. 12, maio/ ago. 1991.

ROMANELLI, G.; NOGUEIRA, M. A.; ZAGO, N. Família e escola: novas perspectivas de análise. Petrópolis: Vozes, 2013.

SAVELI, E. L. Ensino Fundamental de nove anos: bases legais de sua implantação. Práxis Educativa, Ponta Grossa, PR, v. 3, n. 1, p. 67-72, jan./jun. 2008.

SIMMEL, G. Questões fundamentais da Sociologia: indivíduo e sociedade. Rio de Janeiro: Zahar, 2006.

VIANA, M. J. B. Longevidade escolar em famílias de camadas populares: algumas condições de possibilidades. 1998. 264 f. Tese (Doutorado em Educação) - Programa de Pós-Graduação da Faculdade de Educação, Universidade Federal de Minas Gerais, Belo Horizonte, 1998.

WEBER, M. Metodologia das Ciências Sociais. São Paulo: Cortez Editora, 1992.

ZAGO, N. Quando os dados contrariam as previsões estatísticas: os casos de êxito escolar nas camadas socialmente desfavorecidas. Paidéia, Ribeirão Preto, v. 10, n. 18, p. 70-80, jan./jul. 2000 . 